\title{
Small-cell lung cancer growth inhibition: synergism between NMDA receptor blockade and chemotherapy
}

\author{
William G North", \\ Fuli Liu' \\ Konstantin H Dragnev ${ }^{1,2}$ \\ Eugene Demidenko ${ }^{3}$ \\ 'Department of Molecular and \\ Systems Biology, Geisel School of \\ Medicine at Dartmouth College, \\ Hanover, NH, USA; ${ }^{2}$ Department of \\ Medicine, Geisel School of Medicine \\ at Dartmouth College, Hanover, $\mathrm{NH}$ \\ USA; ${ }^{3}$ Department of Community \\ and Family Medicine, Geisel School \\ of Medicine at Dartmouth College, \\ Hanover, NH, USA
}

Video abstract

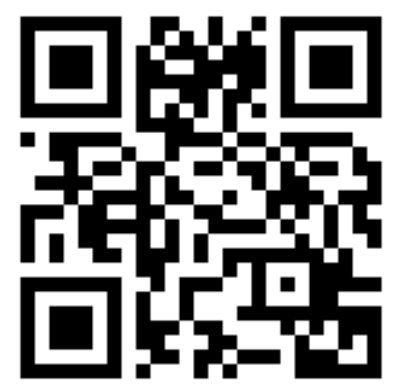

Point your SmartPhone at the code above. If you have a QR code reader the video abstract will appear. Or use: http://youtu.be/UhbmLeOH804

Correspondence: William G North Department of Molecular and Systems Biology, Geisel School of Medicine at Dartmouth College, I Medical Center Drive, Lebanon, NH 03756, USA

Tel +l 6036507736

$\mathrm{Fax}+16036506130$

Email William.G.North@dartmouth.edu
This article was published in the following Dove Medical Press journal: Clinical Pharmacology:Advances and Applications

Background: Small-cell lung cancer (SCLC) has a poor prognosis since there is currently no effective therapy for commonly recurring disease. In our previous study, both primary and recurrent human tumors have been shown to express functional $N$-methyl-D-aspartate (NMDA) receptors, and blockade of these receptors with GluN1 and GluN2B antagonists decreased tumor cell viability in vitro, and growth of tumor xenografts in nu/nu mice.

Materials and methods: In this study, we examine the influence of the GluN2B antagonist ifenprodil and the channel-blocker antagonist memantine, on cell viability and growth of tumor xenografts of recurrent SCLC (rSCLC) in mice.

Results: Both antagonists significantly reduced cell viability and levels of components of the ERK1/2 pathway, increased apoptosis, and at very safe levels significantly reduced the growth of tumors in mice. Each antagonist and topotecan had additive effects to reduce cell viability with significant synergy demonstrated for the case of memantine. More significantly, combination treatments of xenografts in mice with ifenprodil and the chemotherapeutic agent topotecan produced clear additive effects that completely stopped tumor growth. Moreover, the ifenprodil and topotecan combination showed excellent supra-addition or synergy of inhibition for tumors $\leq 300 \mathrm{~mm}$ in size $(P=4.7 \mathrm{E}-4)$. Combination treatment of memantine with topotecan also showed clear addition but, unlike ifenprodil, no synergy for the doses chosen.

Conclusion: Since topotecan is a drug of choice for treatment of rSCLC, our findings suggest that combining this agent with NMDA receptor blockade using the GluN2B antagonist, ifenprodil, will significantly improve patient outcomes.

Keywords: small-cell lung cancer, NMDA receptors, inhibitors, combination therapy

\section{Introduction}

Small-cell lung cancer (SCLC) has an incidence of $\sim 40,000$ new cases in the US each year, ${ }^{1}$ and while primary disease responds well to combination chemotherapies, ${ }^{1-6}$ remission times are limited and there is currently no effective treatment for recurrent disease. ${ }^{1,7}$ New treatments are, therefore, needed that are effective in providing long-term survival for patients with SCLC. Our discovery that all or most SCLC, both primary and recurrent forms, seem to depend for growth on functional tumor $N$-methyl-D-aspartate (NMDA) receptors, ${ }^{8}$ led us to the studies described in this communication that examine the effects on tumor growth of two small antagonists as potential treatments and coupling these antagonists with chemotherapeutic agents as components of potential combination therapies. Although focus here is on recurrent SCLC (rSCLC) and the long-term culture NCI H82, the growth of cultures derived from primary disease (DMS 53, NCI H146, and NCI H345) have also been shown by us to be dependent on functional NMDA receptors. ${ }^{8}$ Receptor inhibition in adenocar- 
cinoma cells and other tumors has been found to impair the ERK1 growth cascade. ${ }^{9,10}$ Functional NMDA receptors are heterotetramers of two GluN1 and two GluN2 protein components that together form ion-channels. ${ }^{11}$ One antagonist examined here is a specific inhibitor of receptors containing the GluN2B protein, ${ }^{12}$ and this protein was found to be common to tumor NMDA receptors. ${ }^{8}$ The other is a channel blocker that recognizes the GluN1 protein. NMDA receptors are critically important for brain function, but have limited peripheral expression. ${ }^{13}$ However, both antagonists readily cross the blood-brain barrier. While a potential complication in the use of tumor NMDA receptor blockade could be expected from the reports of autoimmune encephalitis that can occur in some cancer patients through the generation of antibodies against the GluN1 protein of NMDA receptors, ${ }^{14,15}$ this malady seems to be principally due to a rare central inflammatory reaction. ${ }^{16}$ Moreover, the NMDA antagonists used here have been successfully introduced for therapy in the treatment of conditions such as post-traumatic stress disorder and Alzheimer's disease, without serious side effects. ${ }^{17,18}$ The amount of each antagonist employed was designed to be similar to those that were found by others to be well tolerated in humans. ${ }^{17,18}$ The long-term cell culture of human SCLC used for these tests to grow tumors in nu/ nu mice has been described as "variant" and is representative of recurrent disease. ${ }^{19}$

\section{Materials and methods}

\section{Cultured cell lines}

The variant SCLC cell line, NCI-H82, was obtained from American Type Tissue Culture Collection ([ATCC], Manassas, VA, USA). Cells were grown and maintained in Dulbecco medium or RPMI 1640 (Mediatech, Inc., Manassas, VA, USA) supplemented with 10\% FBS (Sigma Chemicals, Perth, Australia) at cell densities of $10^{5}-5 \times 10^{5} / \mathrm{mL}$ in a humidified atmosphere of $5 \% \mathrm{CO}_{2}$ at $37^{\circ} \mathrm{C}$.

\section{Western blot analysis}

To examine the effects of reagents on the ERK1/2 pathway and poly(ADP-ribose) polymerase (PARP), NCI H82 cells in the RPMI with $10 \%$ FBS were treated for 24 hours at $37^{\circ} \mathrm{C}$ with either $250 \mu \mathrm{M}$ ifenprodil, $250 \mu \mathrm{M}$ memantine, $4 \mu \mathrm{M}$ topotecan, or a combination of topotecan with each NMDA receptor blocker. Cell lysates were prepared by sonication using a RIPA buffer solution (1\% NP-40, 1\% sodium deoxycholate, $0.1 \% \mathrm{SDS}, 150 \mathrm{mM} \mathrm{NaCl}, 25 \mathrm{mM}$ Trizma $\mathrm{HCl}$, and $\mathrm{pH}$ 7.4) with protease inhibitor (HoffmanLa Roche Ltd., Basel, Switzerland), the extracts centrifuged at $12,000 \times g$ for 4 minutes, and the supernatant retained. The protein content of these extracts was assessed by differential absorbance measurements at $215 \mathrm{~nm}$ and $225 \mathrm{~nm}$. Aliquots of each cell lysate $(\sim 25 \mu \mathrm{g}$ protein) or tissue extract $(\sim 50 \mu \mathrm{g}$ protein) were reduced using $50 \mathrm{mM}$ dithiothreitol heated in a boiling water bath for 5 minutes, and separated on $12 \%$ gels by SDS-PAGE using Tris/Glycine/SDS buffer $(25 \mathrm{mM}$ Trizma, $192 \mathrm{mM}$ glycine, $0.1 \% \mathrm{SDS}$, and $\mathrm{pH} 8.3$ ) at a voltage of $50 \mathrm{~V}$ for 10 minutes, and then at $75 \mathrm{~V}$ for $\sim 2$ hours at ambient temperature or at $100 \mathrm{~V}$ for 1 hour at $4^{\circ} \mathrm{C}$. The proteins were transferred onto Immobilon-P polyvinylidene difluoride membrane (EMD Millipore, Billerica, MA, USA) in Tris/glycine/SDS buffer with $6 \%$ methanol, using the MiniPROTEAN 3 system (Bio-Rad Laboratories Inc., Hercules, CA, USA). The membrane was incubated with Superblock PBS buffer (Thermo Fisher Scientific, Waltham, MA, USA), followed by incubation with antibodies against total p42/44 ${ }^{\mathrm{MAPK}}$ (New England Biolabs, Ipswich, MA, USA) or phosphor-p42/44 ${ }^{\mathrm{MAPK}}$ (Cell Signaling Technology, Danvers, MA, USA). Blots were visualized using horseradish peroxidase-labeled goat anti-rabbit antibody (7074; Cell Signaling Technology), SuperSignal West Dura Extended Duration Substrate (Thermo Fisher Scientific), and a Fluorochem 8900 imager. The blots were stripped and incubated with anti-GAPDH (EMD Millipore) or scanned with anti$\beta$-actin (Sigma Chemicals), to ensure equal protein loading.

\section{Cell viability assay}

NCI H82 cells were treated with $0.05 \%$ trypsin, washed in DMEM medium, and plated into 96-well plates at $10^{4}$ cells/ well in medium for 24 hour as previously described. ${ }^{18}$ Incubation for 24, 48, or 72 hours was then performed in DMEM containing $10 \% \mathrm{FBS}$ in the presence or absence of either the channel-blocker antagonist memantine hydrochloride, or the GluN2B antagonist ifenprodil hemitartrate, at differing concentrations $(20-400 \mu \mathrm{M})$, with and without topotecan $(4.0$ $\mu \mathrm{M})$. Alternatively, cells were incubated at differing concentrations $(0.2-16 \mu \mathrm{M})$ of topotecan in the presence and absence of memantine $(25 \mu \mathrm{M})$ or ifenprodil $(20 \mu \mathrm{M})$. For the case of memantine and topotecan combination, synergy was sought at 48 hours of incubation using multiple dosages of both compounds with memantine concentrations ranging from 10 to $40 \mu \mathrm{M}$ and topotecan concentrations ranging from 1.0 to $32 \mu \mathrm{M}$. Finally, in all cases, MTT was added to incubates (Sigma Chemicals; $5 \mathrm{mg} / \mathrm{mL}$ diluted tenfold and incubated for 4 hour at $37^{\circ} \mathrm{C}$, then solubilized with SDS overnight following manufacturer's recommendations). Absorbance at $570 \mathrm{~nm}$ was recorded using a Synergy HT Multi-Detection Microplate Reader. Cell viability was evaluated as percent vehicle control at the corresponding incubation time. 


\section{Treatment of tumor xenografts of rSCLC in mice}

Human subcutaneous tumor xenografts of SCLC cell line NCI H82 were raised in female nu/nu mice by injecting $0.5-1 \times 10^{7}$ cells into the right flank. Tumors were allowed to grow for 2 weeks when they attained sizes of $\sim 300 \mathrm{~mm}^{3}$ and the influence on tumor growth of the channel-blocker receptor antagonist memantine and the GluN2B antagonist, ifenprodil, given i.p., and then examined. Tumor size was assessed by multiplying depth, width, and length, and these measurements were each made in triplicate for each tumor on a daily basis. The sizes obtained for each tumor during the study were expressed as a percentage of the size measured on day zero of treatments. For one study, percentage tumor growth in a control group of animals receiving i.p. PBS vehicle $(\mathrm{n}=8)$ was compared to percentage tumor growth in animals $(n=8)$ receiving ifenprodil ( $2.5 \mathrm{mg} / \mathrm{kg}$ body weight, once daily, and over 10 days). For a second animal study $(\mathrm{n}=8)$, tumor growth in vehicle-treated animals was compared to ifenprodil treatment $(2.5 \mathrm{mg} / \mathrm{kg}$ body weight, once every second day, and over 9 days), topotecan treatment ( $3 \mathrm{mg} / \mathrm{kg}$ body weight on days 0,2 and 4), or a combination treatment of ifenprodil and topotecan. For a third study $(\mathrm{n}=6)$, tumor growth in controls was compared to animals receiving memantine $(5 \mathrm{mg} / \mathrm{kg}$ body weight, once on alternate days, and over 9 days), topotecan ( $2 \mathrm{mg} / \mathrm{kg}$ body weight, on days 0,2 , and 4 ), or a combination of memantine (alternate days) and topotecan. For a fourth study $(n=6)$, control animals were compared to those receiving Cyclophosphamide (50 mg/kg body weight, on days 0,1 , and 2) or a combination of Cyclophosphamide and ifenprodil (2.5 $\mathrm{mg} / \mathrm{kg}$ body weight, once on alternate days, and over 9 days).

\section{Statistical evaluations}

Statistical assessment of results employed GraphPad Prism 7 software and evaluations by ANOVA and the Student-Neumann-Kuels test. Longitudinal growth data of tumors were evaluated using repeated measures ANOVA. Significance was determined to be present for $P<0.05$. The $P$-value for synergy was computed as the $t$-test for testing the null hypothesis that combination index $(\mathrm{CI})=1$ (drugs act independently). To evaluate synergy in vitro the CI of Chou-Talalay was used. ${ }^{20}$ To evaluate synergy in mouse tumor growth experiments, the method based on the comparison of the rate of growth as described in Demidenko was used. ${ }^{21}$ For this estimate for the rate of growth in each group, the function lme from the library nlme of the statistical package $\mathrm{R}$ is employed.

\section{Assurance for animal studies}

Animal studies were approved by the IACUC of Dartmouth College, an AAALAC approved facility, under animal welfare assurance number A3259-01.

\section{Results \\ Ifenprodil, memantine, and topotecan reduce the ERI/2 pathway with additive effects}

Key components of the ERK $1 / 2$ pathway, p42 ${ }^{\mathrm{MAPK}}$, and phosphoro-p42/44 ${ }^{\mathrm{MAPK}}$ were dramatically reduced by incubating cells for 24 hours with ifenprodil or memantine. Results for ifenprodil are illustrated in Figure 1. The same amount $(250 \mu \mathrm{M})$ of antagonist reduced total $\mathrm{p} 42 / 44^{\mathrm{MAPK}}$ to about one-half and phosphoro-p $42 / 44^{\mathrm{MAPK}}$ to about one-third of controls. However, while $\mathrm{p} 42^{\mathrm{MAPK}}$ was decreased to one-third

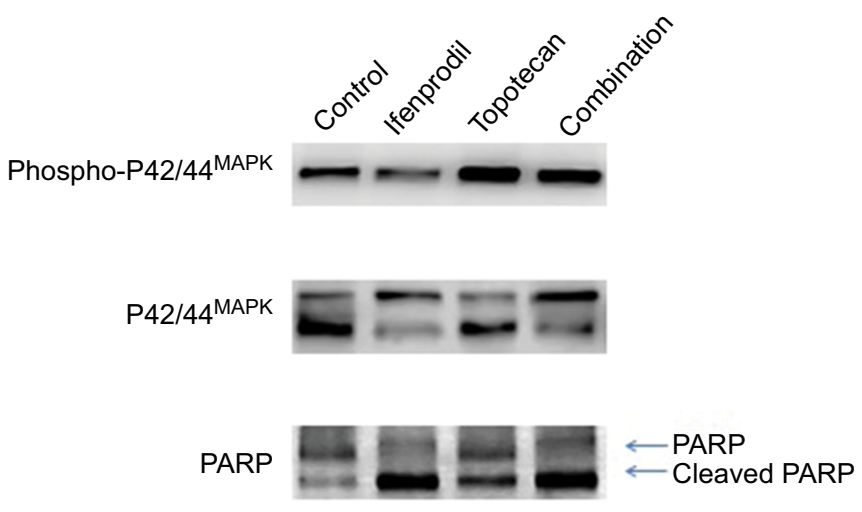

Figure I Influence of 24-hour incubation of $\mathrm{NCl} \mathrm{H82} \mathrm{cells} \mathrm{by} \mathrm{ifenprodil} \mathrm{(} 250 \mu \mathrm{M})$, topotecan $(4 \mu \mathrm{M})$, or a combination of these compounds, on p42/44MAPK, phosphorp42/44 MAPK , and intact and $89 \mathrm{Kd}$ breakdown product of PARP.

Notes: Compared to controls, ifenprodil significantly increased $\mathrm{p}^{44^{\text {MAPK }}}(\times 1.53)$, reduced $\mathrm{p} 42^{\text {MAPK }}(\times 0.31)$, and reduced phosphor-p42/44 ${ }^{\text {MAPK }}(\times 0.59)$. Topotecan had the opposite effect on levels of these proteins $(\times 0.68, \times 0.70$, and $\times 1.96$, respectively), while the drug combination favored the influence of ifenprodil of the first two proteins, but phosphor-p42/44 MAPK remained increased $(\times 1.95, \times 0.40$, and $\times 1.41$, respectively). For PARP, ifenprodil produced a threefold reduction of intact protein $(\times 0.38)$ and a fivefold increase in the $89 \mathrm{Kd}$ fragment $(\times 5.21)$, topotecan maintained the level of intact protein $(\times 0.98)$ while increasing the level of fragment twofold $(\times 2.23)$, and drug combination produced a twofold reduction of intact protein $(\times 0.45)$ and an almost sixfold increase of $89 \mathrm{Kd}$ fragment $(\times 5.48)$.

Abbreviation: PARP, poly(ADP-ribose) polymerase. 
of controls, p44 ${ }^{\mathrm{MAPK}}$ was actually increased almost twofold by receptor blockade. Topotecan $(4 \mu \mathrm{M})$ marginally reduced levels of both $\mathrm{p} 42^{\mathrm{MAPK}}$ and $\mathrm{p} 44^{\mathrm{MAPK}}$ to about two-thirds of controls while phosphoro-p42/44 ${ }^{\mathrm{MAPK}}$ was increased almost twofold. When NMDA receptor antagonist was given together with topotecan, the effects on $\mathrm{p} 42 / 44^{\mathrm{MAPK}}$ and phosphorop42/44 ${ }^{\mathrm{MAPK}}$ by antagonist largely prevailed.

The DNA repair proteins, PARP, of rSCLC cells were reduced to about one-third of controls by ifenprodil and memantine, and the amount of $89 \mathrm{Kd}$ breakdown product of this enzyme representing caspase activity and cell apoptosis was increased about fivefold (Figure 1), topotecan produced no change in the intact protein and a twofold increase in breakdown product, and drug combination produced about a twofold reduction of intact protein and a sixfold increase of breakdown product.

\section{Combination ifenprodil or memantine blockade with topotecan decreases cell viability with additive effects: synergy with memantine}

Ifenprodil, memantine, and topotecan all reduced the viability of rSCLC cells and the results are summarized in Table 1. When NCI-H82 rSCLC cells were treated for 48 hours with increasing concentrations of the GluN2B antagonist ifenprodil hemitartrate, there were dramatic reductions in cell viability indexed by the MTT method with significant changes $(P<0.01)$ produced with doses of $<50 \mu \mathrm{M}$ antagonist, and a reduction to less than $50 \%$ controls (IC50) produced by doses of $>106 \mu \mathrm{M}$. Similarly the channel-blocker antagonist memantine reduced cell viability and to a similar degree as ifenprodil, such that significance was observed at $<50 \mu \mathrm{M}$ antagonist $(P<0.01)$, and reductions to less than $50 \%$ controls produced by concentrations of $>196 \mu \mathrm{M}$. For topotecan

Table I Dose of NMDA-receptor antagonist (ifenprodil and memantine) or topotecan, alone or in combination, found to reduce $\mathrm{rSCLC}$ cell line $(\mathrm{NCl}-\mathrm{H} 82)$ viability to $50 \%$ control (IC 50) after 48 hours of incubation

\begin{tabular}{|l|l|l|}
\hline Drug & Combined treatment & $\begin{array}{l}\text { IC50 } \\
(\boldsymbol{\mu M})\end{array}$ \\
\hline \multirow{3}{*}{ Ifenprodil } & - & 106 \\
\hline \multirow{3}{*}{ Memantine } & Topotecan $(4 \mu \mathrm{M})$ & 7.3 \\
\hline \multirow{3}{*}{ Topotecan } & - & 195 \\
\cline { 2 - 3 } & Topotecan $(4 \mu \mathrm{M})$ & 51.3 \\
\hline & - & 5.7 \\
\cline { 2 - 3 } & Ifenprodil $(20 \mu \mathrm{M})$ & 2.3 \\
\cline { 2 - 3 } & Memantine $(25 \mu \mathrm{M})$ & 2.0 \\
\hline
\end{tabular}

Abbreviations: NMDA, N-methyl-D-aspartate; rSCLC, recurrent small-cell lung cancer. incubations for 48 hours at concentrations in the range of $1.0-35 \mu \mathrm{M}$, significant reductions were obtained with $1.0 \mu \mathrm{M}$ and a $50 \%$ reduction by $5.7 \mu \mathrm{M}$. Combining topotecan and NMDA receptor antagonists produced clear additive effects on reducing cell viability (Figure $2 \mathrm{~A}-\mathrm{D}$ ). A dose of $4 \mu \mathrm{M}$ topotecan added in the presence of increasing amounts of ifenprodil or memantine produced increased sensitivity at all concentrations with a reduced cell viability to $50 \%$ (IC50) produced by $\sim 10 \mu \mathrm{M}$ ifenprodil and by $\sim 50 \mu \mathrm{M}$ of memantine. Alternatively, as little as $20 \mu \mathrm{M}$ and $25 \mu \mathrm{M}$ of NMDA receptor antagonist added to increasing amounts of topotecan saw increased sensitivity throughout and IC50s achieved by only $\sim 2 \mu \mathrm{M}$ topotecan. When multiple combination dosing was performed between memantine and topotecan, a statistically significant synergy was demonstrated with a mean CI of 0.734 and $P$-value of 0.007 .

\section{Tumor growth is largely prevented by ifenprodil: synergy with topotecan}

Given at a well-tolerated dose, the GluN2B antagonist ifenprodil, largely prevented growth of tumor xenografts of rSCLC generated from NCI H82 cells in nu/nu mice (Figure $3 \mathrm{~A}-\mathrm{C}$ ). For the first study, while vehicle-treated control tumors rapidly increased in size, ifenprodil treatment of tumors, on a daily basis, decreased their size by $\sim 30 \%$, and maintained them at a size below that at day 0 until treatment ceased at day 10. Thereafter, tumors began to recover and grow but at the same rate as control tumors so that at day 18, ifenprodil-treated tumors had grown by less than half of controls (Figure $3 \mathrm{~A}, P<0.001$ ). The safe nature of the dose of drug given was reflected by obtaining the superimposed curves for changes in body weight of vehicle control and ifenprodil-treated animals (data not shown). For the second study (Figure 3B), topotecan and ifenprodil treatment alone slowed tumor growth compared to vehicle-treated controls so that each agent restricted the rise in tumor size to about 2.5 -times by day 16 , while controls rose to an average of 9.2-times. Tumor doubling times were 4 days for controls, 9 days for topotecan treatment, and 12 days for ifenprodil treatment. When results on individual animals in the second study are plotted (Figure 3C), it is seen that there is considerable scatter within each of the three groups. Combining topotecan and ifenprodil treatments seemed to arrest all growth over the 16 days of observation, and the tumors of all individual animals behaved in a similar manner with little scatter. From this study, there was clear addition through the topotecan and ifenprodil combination $(P<0.01)$ with synergy displayed for tumors initially at $\leq 300 \mathrm{~mm}^{3}$ in size $(P=4.7 \mathrm{E}-4)$. In a similar fashion, combining ifenprodil with cyclophosphamide treat- 

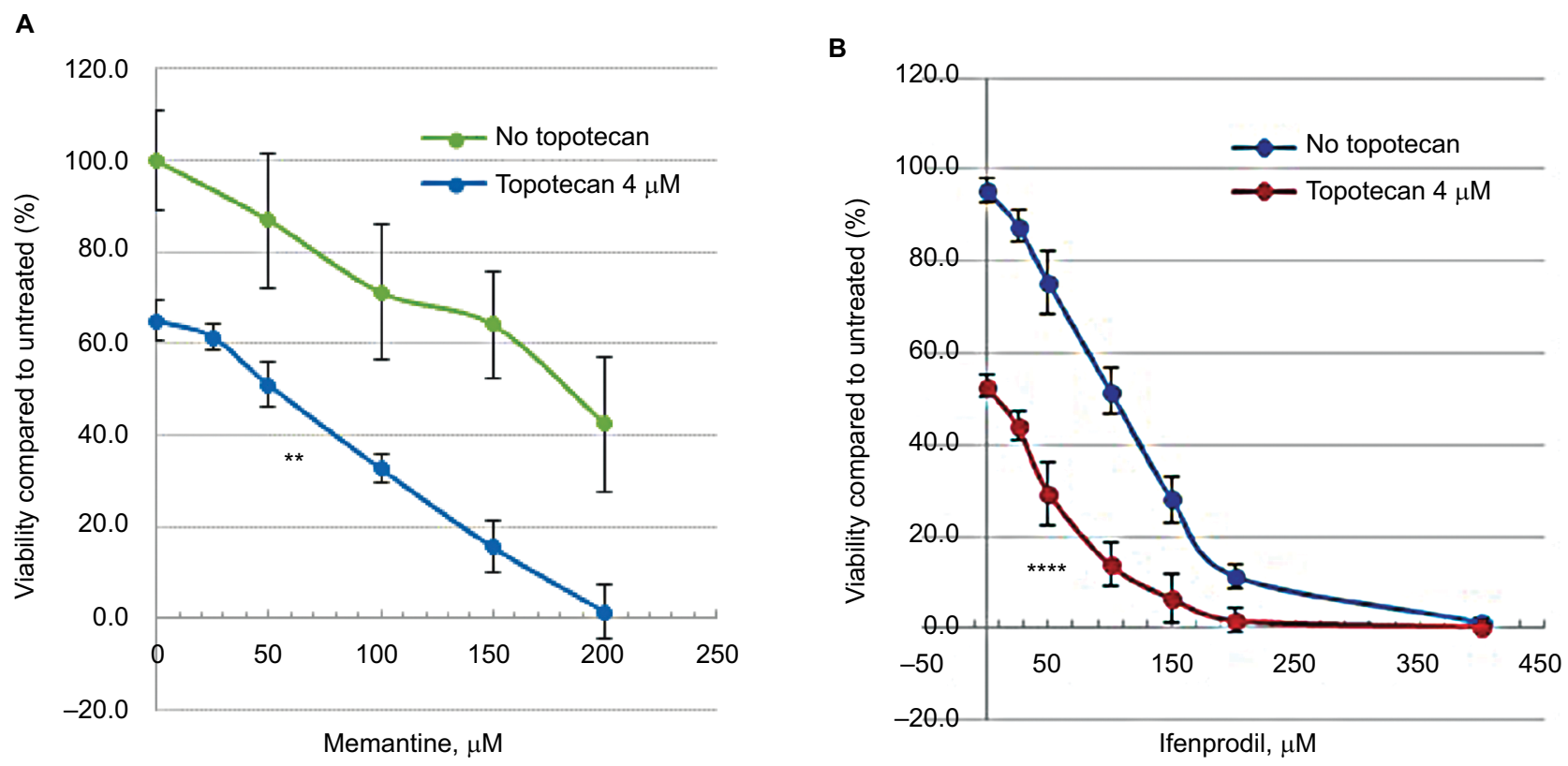

C
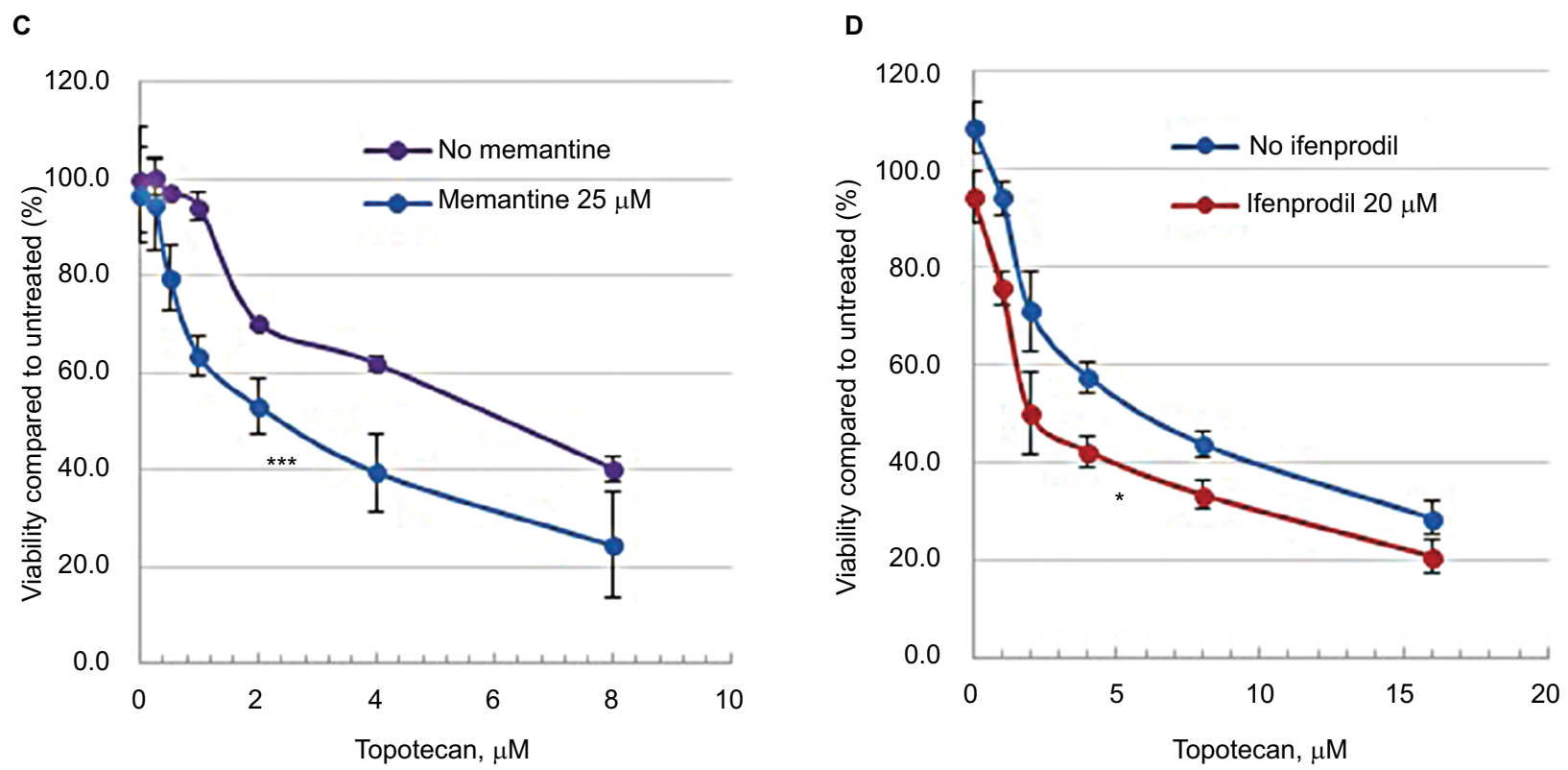

Figure 2 The influence of ifenprodil, memantine, and topotecan treatment for 48 hours on $\mathrm{NCl} \mathrm{H82} \mathrm{SCLC} \mathrm{cell} \mathrm{viability}(\mathrm{n}=8)$ compared to untreated controls.

Notes: (A) Memantine $\mathrm{HCl}(20-400 \mu \mathrm{M})$ in the presence and absence of $4 \mu \mathrm{M}$ topotecan; (B) ifenprodil hemitartrate $(20-400 \mu \mathrm{M})$ in the presence and absence of $4 \mu \mathrm{M}$ topotecan ; (C) topotecan (I-16 $\mu \mathrm{M})$ in the presence and absence of $25 \mu \mathrm{M}$ memantine $\mathrm{HCl}$; and (D) topotecan (I-16 $\mu \mathrm{M})$ in the presence and absence of $25 \mu \mathrm{M}$ ifenprodil hemitartrate. Values ( \pm SEM) are expressed as the percentage proliferation exhibited by cells in the absence of inhibitor. Drug effects were additive so that in all cases the dose giving an IC50 was significantly reduced: memantine plus topotecan (196 to $\sim 50 \mu \mathrm{M}, * * P<0.004$ ); ifenprodil plus topotecan ( 106 to $\sim 7 \mu \mathrm{M}$, $* * * * P<0.0001$ ); topotecan plus memantine (5.7 to $\sim 2 \mu \mathrm{M}$, $\left.{ }^{*} * P<0.003\right)$; and topotecan with ifenprodil (5.7 to $\sim 2 \mu \mathrm{M},{ }^{*} P<0.009$ ).

Abbreviation: SCLC, small-cell lung cancer.

ment produced a clear additive effect $(P<0.03)$, preventing tumor growth (data not shown).

\section{Tumor growth is reduced by memantine: addition but no synergy with topotecan combination}

Treating rSCLC tumors with memantine $(5 \mathrm{mg} / \mathrm{kg}$ on alternate days) significantly $(P<0.01)$ reduced their growth by day
13 compared to controls by almost $40 \%$ on average (doubling time going from 4 days to 6 days). These memantine-treated tumors grew to about 4-times their day 0 size (Figure 4). The amount of topotecan used ( $2 \mathrm{mg} / \mathrm{kg}$ days 0,2 , and 4$)$ also significantly $(P<0.01)$ decreased growth of such tumors but by $\sim 20 \%$ of controls (doubling time from 4 days to 5 days). These topotecan-treated tumors grew to about 6-times their day 0 size. When the two substances were combined for 
A

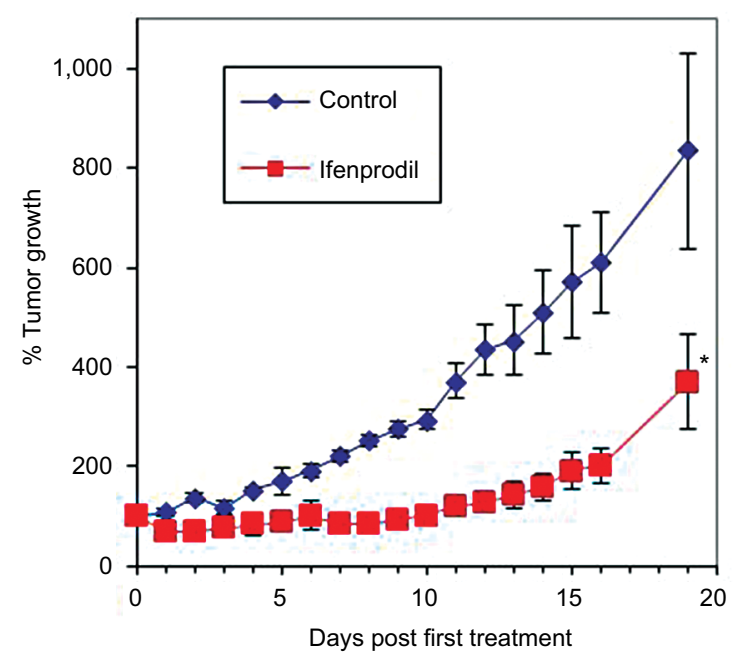

B

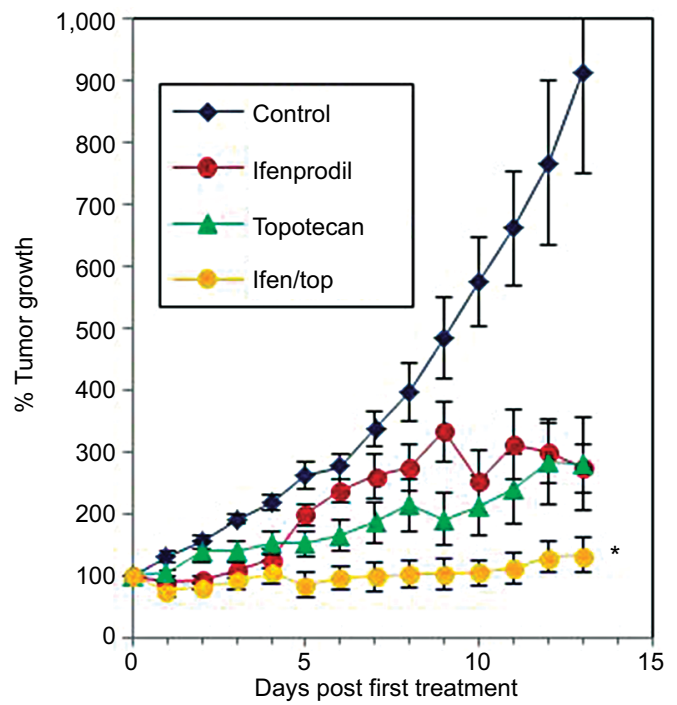

C
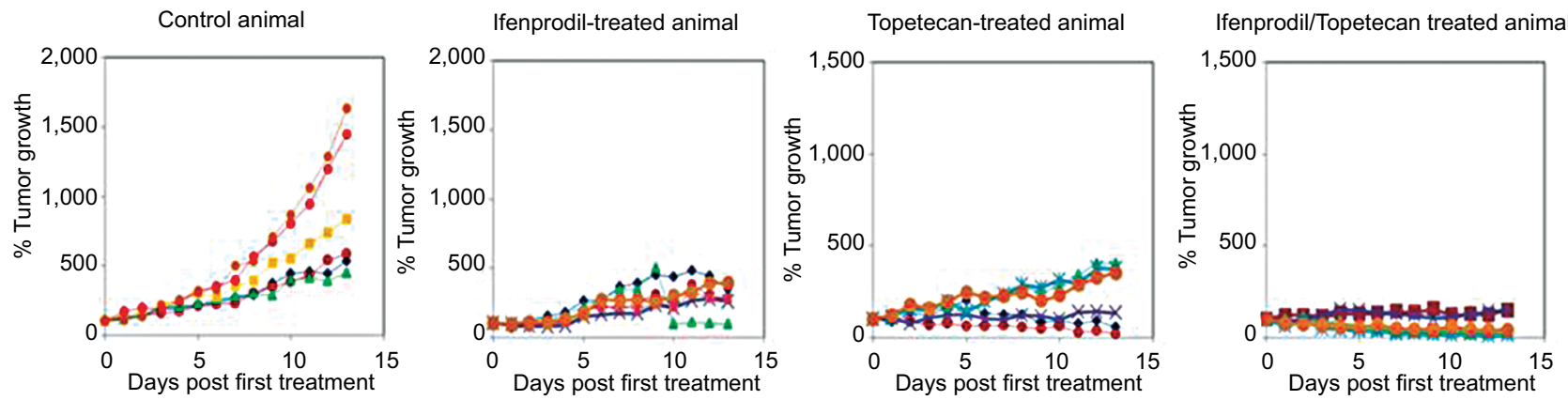

Figure 3 Influence of ifenprodil blockade of tumor NMDA receptors on the growth of human rSCLC xenografts in nu/nu mice and synergy with topotecan. Notes: (A) Administration of ifenprodil in daily dose of $2.5 \mathrm{mg} / \mathrm{kg}$ body weight for 10 days (days 0 through 9) shrank tumor size and prevented growth during treatment $(* P<0.00 \mathrm{I}, \mathrm{n}=8)$; (B) administration of ifenprodil every second day $(2.5 \mathrm{mg} / \mathrm{kg}$ body weight) over 9 days (days 0 through 8$)$, topotecan on days 0,2 , and 4 ( $3 \mathrm{mg} / \mathrm{kg}$ body weight), or a combination of both treatments $(n=6)$; and $(\mathbf{C})$ animals of $(\mathbf{B})$ shown as individual curves. While average tumor growth is reduced by half by each drug, combination treatment completely blocked growth in all animals $\left({ }^{*} P<0.00 \mathrm{I}\right.$ vs vehicle, $P<0.0 \mathrm{I}$ vs either agent alone) with marked synergy for smaller tumors $(P=4.7 \mathrm{E}-4)$. All treatments had no apparent effect on animal health.

Abbreviations: NMDA, N-methyl-D-aspartate; rSCLC, recurrent small-cell lung cancer.

treatment, effects were additive $(P<0.03)$ such that tumor growth was reduced by about $60 \%$ of controls (doubling time from 4 days to 7 days). Combination-treated tumors grew to about 3 -times their day 0 size. However, for the conditions used in the case of memantine and topotecan combination, there was clear addition but no synergy using the method of Demidenko. $^{21}$

\section{Discussion}

The studies conducted are believed to provide firm evidence that NMDA receptor blockade can be safely and effectively used in the treatment of rSCLC. This is particularly so for the GluN2B antagonist ifenprodil, especially if included with current treatment by the chemotherapeutic agent topotecan. Ifenprodil at $2.5 \mathrm{mg} / \mathrm{kg}$ body weight given daily reduced the size of tumors over the course of treatment, and given on alternate days significantly reduced the growth threefold. When the lower dose was combined with topotecan, there was complete tumor growth suppression with clear synergy for smaller tumors $\left(\leq 300 \mathrm{~mm}^{3}\right)$. Topotecan is currently the treatment of choice for rSCLC. ${ }^{6,7}$ While our studies were performed in mice, the mouse should be a reasonable model to use since ifenprodil has similar activities in humans and has a similar half-life. ${ }^{22-26}$ It did not negatively impact health according to body weight of animals. The ifenprodil dosage here was higher than is customarily used in humans, but is nevertheless of a similar magnitude. The topotecan dosage employed was similar to that proposed by others. ${ }^{27-29}$ SCLC recurrent disease in patients is generally resistant to treatment and 


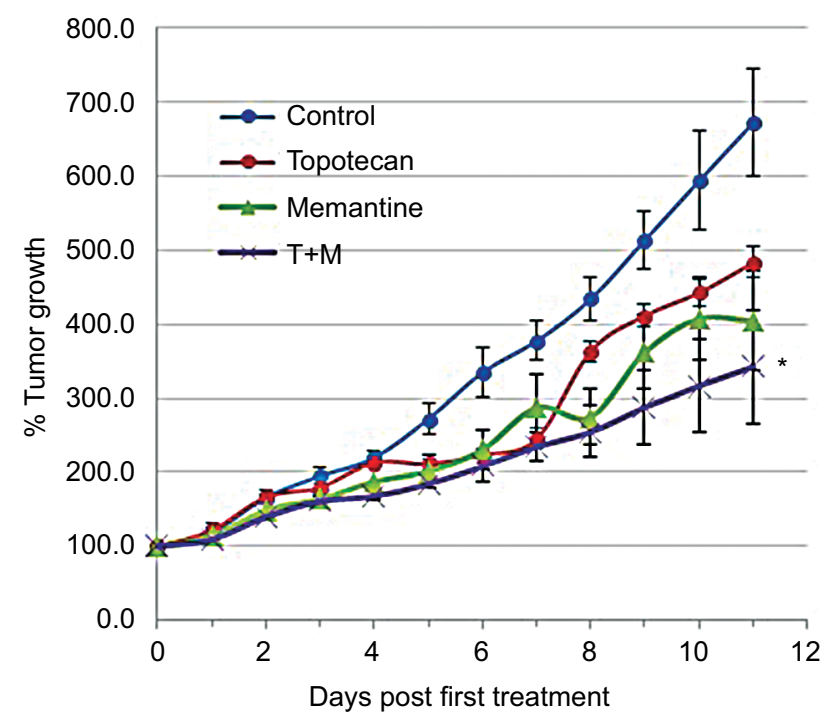

Figure 4 Influence of memantine blockade of tumor NMDA receptors on the growth of human rSCLC xenografts in nu/nu mice and combination effects with topotecan.

Notes: Administration of memantine every second day ( $5 \mathrm{mg} / \mathrm{kg}$ body weight) over 9 days (days 0 through 8 ), topotecan on days 0,2 , and 4 ( $3 \mathrm{mg} / \mathrm{kg}$ body weight), or a combination of both treatments $(n=6)$. While average tumor growth is reduced by $\sim 30 \%$ and $\sim 40 \%$ by each drug ( $* P<0.0$ I vs vehicle), and combination treatment was additive to $\sim 50 \%$, there was clear addition ( ${ }^{*} P<0.03$ vs either agent alone), but no drug synergy. All treatments had no apparent effect on animal health.

Abbreviations: NMDA, N-methyl-D-aspartate; rSCLC, recurrent small-cell lung cancer.

while topotecan is the preferred therapy, results when given alone are mixed. ${ }^{30-32}$

Like ifenprodil, the channel-blocker memantine, given on alternate days at $5 \mathrm{mg} / \mathrm{kg}$ body weight, ${ }^{33}$ reduced the growth of tumors, and this reduction was increased when the drug was given with topotecan. However, unlike combination effects with ifenprodil, for the memantine combination with this chemotherapeutic agent, there was clearly no synergy for the amounts used. The dosage of memantine employed here was selected to generate in mice similar circulating levels $(40-170 \mathrm{ng} / \mathrm{mL})$ produced in patients being treated for Alzheimer's disease. The half-life of memantine in mice is $15-20$ times shorter than in humans. ${ }^{34}$

Despite differences between ifenprodil and memantine in terms of the above combination treatments of xenografts in mice, the compounds have very similar effects on NCI H82 cells in vitro. Both drugs produced a dose-dependent decrease in cell viability with IC50s produced by $\sim 150 \mu \mathrm{M}$ after 48 hours, and this sensitivity was increased in the presence of $4 \mu \mathrm{M}$ topotecan so that an IC50 was produced by, respectively, $7 \mu \mathrm{M}$ and $51 \mu \mathrm{M}$ of antagonist. In a similar manner, the dose-dependent fall in cell viability produced by topotecan was increased in the presence of $20 \mu \mathrm{M}$ ifenprodil or $25 \mu \mathrm{M}$ memantine from an IC50 of about $6 \mu \mathrm{M}$ to about $2 \mu \mathrm{M}$. In addition, over a combined range of concentrations, memantine and topotecan showed clear synergy with NCI H82 cancer cells in vitro.

\section{Conclusion}

Regarding mechanisms, we have previously shown the presence of GluN1 and GluN2B proteins for NMDA receptors on SCLC so, despite both drugs having other actions, it is likely that memantine is operating as an antagonist through interaction with GluN1 and ifenprodil as an antagonist through interaction with both GluN1 and GluN2B. ${ }^{11,12}$ Others ${ }^{9}, 10$ have shown that blockade of NMDA receptors with other antagonists in lung adenocarcinoma and other cancer cells produced a substantial reduction in phosphorylated $\mathrm{p} 42 / 44^{\mathrm{MAPK}}$, and 24 hour incubations with either ifenprodil or memantine produced similar reductions in phosphor-p42/44 ${ }^{\mathrm{MAPK}}$, while each antagonist reduced total $\mathrm{p} 42 / 44^{\mathrm{MAPK}}$ in the same differential substantial manner by reducing $\mathrm{p} 42^{\mathrm{MAPK}}$ to about one-third while increasing $\mathrm{p} 44^{\mathrm{MAPK}}$ about twofold. However, the enhanced effects of combination on cell viability seen with topotecan did not appear to involve the ERK1/2 cascade, because the chemotherapeutic agent only seemed to marginally affect this system and not add to the effects seen with the antagonists.

Both ifenprodil and memantine treatments in vitro substantially reduced cell levels of the intact DNA repair protein PARP in rSCLC cells when corrected for GAPDH, while increasing PARP1 breakdown fivefold to the $89 \mathrm{Kd}$ product, representing substantially increased caspase activity. This showed that the antagonists were promoting cancer cell apoptosis while reducing DNA repair through PARP1. Pietanza et $\mathrm{al}^{7}$ have reported common overexpression of the DNA repair proteins PARP1, Chk1, BRCA-1, and RAD51 in SCLC and suggest that this might represent primary resistance to agents like topotecan, which is an inhibitor of topoisomerase- 1 and reduces repair of double-stranded DNA breaks. Reducing levels of DNA repair proteins, as shown here for active PARP1, could be one mechanism through which NMDA antagonists enhance the actions of topotecan.

While the mechanism for selective synergy of NMDA receptor blockade with topotecan is still to be resolved, it is clear that ifenprodil and topotecan together seem to exert a profound effect on tumor xenografts of rSCLC. The data from this and our other studies allow us to conclude that there is good reason outcomes for patients with this disease could be significantly improved by including NMDA receptor blockade by ifenprodil with currently preferred topotecan treatment.

\section{Acknowledgments}

We are indebted to Aki Bowers and Cindy Sun for their technical support. This work was supported in part by PHS grant 
R21 CA167329 to WGN, and NIH/NCI Israel (PI) Cancer Center Support Grant P30 CA23108-37. Dartmouth College has taken out a patent on subject matter discussed here.

\section{Author contributions}

WGN drafted the manuscript and was the chief architect of the research conducted. WGN and FL were involved in performing cell-culture, in vitro viability studies, and Western Analysis, and KHD assisted in their planning. FL actively participated in performing and planning animal studies with WGN, and ED was responsible for performing statistical analysis. All authors contributed to data analysis, drafting or revising the article, gave final approval of the version to be published, and agree to be accountable for all aspects of the work.

\section{Disclosure}

The authors report no conflicts of interest in this work.

\section{References}

1. American Cancer Society. Cancer Facts and Figures. 2016.

2. Wampler GL, Heim WJ, Ellison NM, Ahlgren JD, Fryer JG. Comparison of cyclophosphamide, doxorubicin, and vincristine with an alternating regimen of methotrexate, etoposide, and cisplatin/cyclophosphamide, doxorubicin, and vincristine in the treatment of extensive-disease smallcell lung carcinoma: a Mid-Atlantic Oncology Program study. J Clin Oncol. 1991;9(8):1438-1445.

3. Cook RF, Miller YE, Bunn PA Jr. Small cell lung cancer: etiology, biology, clinical features, staging, and treatment. Curr Probl Cancer. 1993;17(2):73-141.

4. Van Zandwijk N. Are we moving towards continuous treatment in small cell lung cancer (SCLC)? Anticancer Res. 1994;14(1B):309-311.

5. Zangemeister-Wittke U, Stahel RA. Novel approaches to the treatment of small-cell lung cancer. Cell Mol Life Sci. 1999;55(12):1585-1598.

6. Ciombor KK, Rocha Lima CM. Management of small cell lung cancer. Curr Treat Options Oncol. 2006;7(1):59-68.

7. Pietanza MC, Byers LA, Minna JD, Rudin CM. Small cell lung cancer: will recent progress lead to improved outcomes? Clin Cancer Res. 2015;21(10):2244-2255.

8. North WG, Gao G, Jensen A, Memoli VA, Du J. NMDA receptors are expressed by small cell lung cancer and are potential targets for effective treatment. Clinical Pharmacol. 2010;2:31-40.

9. Stepulak A, Sifringer M, Rzeski W, et al. NMDA antagonist inhibits the extracellular signal-regulated kinase pathway and suppresses cancer growth. Proc Natl Acad Sci USA. 2005;102(43):15605-15610.

10. Li L, Hanahan D. Hijacking the neuronal NMDAR signaling circuit to promote tumor growth and invasion. Cell. 2013;153(1):86-100.

11. Carpenter D. NMDA receptors and the molecular mechanisms of excitotoxicity. In: Johnson P., Boldyrev A.A., editors. Oxidative Stress at the Molecular, Cellular, and Organ Levels. Trivandrum: Research Signpost; 2002:77-88.

12. Gallagher MJ, Huang H, Pritchett DB, Lynch DR. Interactions between ifenprodil and the NR2B subunit of the $N$-methyl-D-aspartate receptor. J Biol Chem. 1996;271(16):9603-9611.

13. Hinoi E, Takarada T, Ueshima T, Tsuchihashi Y, Yoneda Y. Glutamate signaling in peripheral tissues. Eur J Biochem. 2004;271(1):1-13.
14. Tüzün E, Zhou L, Baehring JM, Bannykh S, Rosenfeld MR, Dalmau J. Evidence for antibody-mediated pathogenesis in anti-NMDAR encephalitis associated with ovarian teratoma. Acta Neuropathol. 2009;118(6):737-743.

15. Dalmau J, Gleichman AJ, Hughes EG, et al. Anti-NMDA-receptor encephalitis: case series and analysis of the effects of antibodies. Lancet Neurol. 2008;7(12):1091-1098.

16. Will A, Akalin M. Paraneoplastic limbic encephalitis with NMDA receptor (NR1) antibodies in breast cancer. Neurology. 2012;78(Meeting Abstracts 1):S08.007.

17. Sasaki T, Hashimoto $\mathrm{K}$, Okawada $\mathrm{K}$, et al. Ifenprodil for the treatment of flashbacks in adolescent female posttraumatic stress disorder patients with a history of abuse. Psychother Psychosom. 2013;82(5): 344-345.

18. Sonkusare SK, Kaul CL, Ramarao P. Dementia of Alzheimer's disease and other neurodegenerative disorders-memantine, a new hope. Pharmacol Rev. 2005;51:1-17.

19. Gazdar AF. Morphologic and other forms of heterogeneity in small cell lung cancer: what can we learn from them? J Thorac Oncol. 2018;13(2):148-150.

20. Chou TC. Drug combination studies and their synergy quantification using the Chou-Talalay method. Cancer Res. 2010;70(2):440-446.

21. Demidenko E. Mixed Models: Theory and Applications with R. 2nd ed. Hoboken: Wiley; 2013.

22. North WG, Liu F, Tian R, Abbasi H, Akerman B. NMDA receptors are expressed in human ovarian cancer tissues and human ovarian cancer cell lines. Clin Pharmacol. 2015;7:111-117.

23. Raybuck JD, Hargus NJ, Thayer SA. A GluN2B-selective NMDAR antagonist reverses synapse loss and cognitive impairment produced by the HIV-1 protein tat. J Neurosci. 2017;37(33):7837-7847.

24. Mccauley JA, Bednar RA, Gaul S, et al. Preclinical pharmacology and pharmacokinetics of CERC - 301, a GluN2B - selective $N$ methyl - D - aspartate receptor antagonist. Pharmacol Res Perspect. 2015:e0198.

25. Yang J, Lu C, Song W, et al. Determination of ifenprodil by LC-MS/ MS and its application to a pharmacokinetic study in healthy Chinese volunteers. Acta Pharmaceutica Sinica B. 2013;3(3):180-184.

26. Yang B, Chen Y, Xiang R, Yang D, Xia P, Liu S. Determination of ifenprodil in human plasma using liquid chromatography with electrospray tandem mass spectrometry. Se Pu. 2008;26(3):322-326.

27. Guichard S, Montazeri A, Chatelut E, Hennebelle I, Bugat R, Canal P. Schedule-dependent activity of topotecan in OVCAR-3 ovarian carcinoma xenograft. Clin Cancer Res. 2001;7(10):3222-3228.

28. Yi XF, Fan SM, Yao M, Feng YJ. Comparison of the efficacy and toxicity profile between intraperitoneal and intravenous topotecan in human ovarian tumor xenografts. Beijing Da Xue Xue Bao Yi Xue Ban. 2006;38(1):88-91.

29. Hollingshead MG. Antitumor efficacy testing in rodents. JNCI: J Nat Cancer Inst. 2008;100(21):1500-1510.

30. Ardizzoni A. Topotecan in the treatment of recurrent small cell lung cancer: an update. Oncologist. 2004;9(suppl_6):4-13.

31. Eckardt JR, von Pawel J, Pujol JL, et al. Phase III study of oral compared with intravenous topotecan as second-line therapy in small-cell lung cancer. J Clin Oncology. 2007;25(15):2086-2092.

32. Hagmann R, Hess V, Zippelius A, Rothschild SI. Second-line therapy of small-cell lung cancer: topotecan compared to a combination treatment with adriamycin, cyclophosphamide and vincristine (ACO) - a single center experience. $J$ Cancer. 2015;6(11):1148-1154.

33. Li F, Chen X, Wang F, et al. Chronic pretreatment with memantine prevents amyloid-beta protein-mediated long-term potentiation disruption. Neurodegen Dis Neural Regen. 2013;8:49-55.

34. Beconi MG, Howland D, Park L, et al. Pharmacokinetics of memantine in rats and mice. PloS Curr. 2012;3:RRN291. 
Clinical Pharmacology: Advances and Applications is an international, Visit http://www.dovepress.com/testimonials.php to read real quotes peer-reviewed, open access journal publishing original research, reports, from published authors.

reviews and commentaries on all areas of drug experience in humans.

The manuscript management system is completely online and includes a very quick and fair peer-review system, which is all easy to use.

Submit your manuscript here: https://www.dovepress.com/clinical-pharmacology-advances-and-applications-journal 